\title{
Preparation of Magnetorheological fluids: A Research
}

\author{
Aditya Devol, Chandan Kumar
}

\begin{abstract}
Magnetorheological fluids (MRFs) are just one of those varieties of wise substances, whose viscosity improves appreciably within the existence of the magnetic area. Distributing magnetizable particles that were micro-size to some store fluid using additives that are additive prepares these fluids. The fluids' major quality would be the capacity to differ later employing a magnetic area, only two or three milliseconds. Very low magnetorheological uncertainty and result of MRFs would be definitely the issues contrary to the use of MRFs technologies in businesses. Numerous techniques are suggested and employed by investigators to successfully increase the equilibrium of those fluids as well as the result. This study's focus would be to give an overview on procedures of insertion and planning of MR fluids. What's more, use of MR fluids and rheological versions have been reviewed inside this research.
\end{abstract}

\section{INTRODUCTION}

Various wise substances are identified thus far, probably the most crucial which can be magnetic suspensions (magnetorheological fluids along with ferrofluids), electrorheological fluids, including conductive substances and shape-memory metals [1]. Suspensions are fluids whose faculties vary substantially from the existence of the magnetic area. Rabinow introduced fluids from America National Bureau of Standards [ 4 ]. Particles at MRFs are multi-domain the applying form of the outside magnetic field causes leads in interactions among the contaminants also a dipole in every particle. This also could lead all through the suspension to the creation of the system of agglomerates. Like a consequence that the magnetorheological reversibly varies from country into country within the existence of the magnetic field [2]. Viscosity of MRFs can be actually really just a purpose of provider petroleum possessions, suspending representatives and quantity percentage of their contaminants [5].Features of fluids like viscosity and generate pressure can be manipulated by using a magnetic area. At the existence of the outside magnetic field, the liquid demonstrates behaviour that's characterized with way of a produce strain and also a rise in viscosity[1,6]. Viscosity of this liquid depends nitude and management of the magnetic field and also speed [7]. Rheological features along with viscosity of MRFs might be manipulated by controlling strength of the magnetic field [8]. Generally in the majority of uses of magnetorheologicalfluids, answer period of MRFs gets got the best relevance. This period changes within the scope of 10--20 ms predicated on circuit designing that is magnetic.

Revised Version Manuscript Received on 10 September, 2019.

AdityaDevol, Mechanical Engineering, Noida Institute of Engineering and Technology, UttarPradesh, India.

(Email: research.paper@niet.co.in)

Dr. Chandan Kumar, Mechanical Engineering, Noida Institute of Engineering and Technology, UttarPradesh, India.

(Email: research.paper@niet.co.in)
MRFs are still among the electrome- ports for software that are mechanical. Even a magnetorheological fluid-based in Regular density and its own makeup has the capability to exhibit lively return strain upto a hundred $\mathrm{kPa}$ [9]. Software and A few traits of suspension are sum- . Considering that magnetorheology's discovery, investigators have researched fresh buildings of their faculties, MRFs and also factors. Within an review that is complete, Charles [10] classified and researched faculties of fluids. Inside this function, the synthesis processes of methods of these aggregation in addition to particles had been investigated. Vicente et al. [1-1] examined development from the arrangement of MR suspension behavior. They dedicated to regulating version of MRFs and talked in specifics relating to this. Carlson and Jolly [5] have researched the traits of magnetorheological fluids, including magazine - netorheological foams along with magnetorheological elastomers, as well as his or her own software. Their reports demonstrated that software of technological innovation that was magnetorheological contribute to creating constructions of those substances. In a effort to comprehend the rheology of all magnetorheological fluids," Bossis et al. [12 ] analyzed On account of this advancement in MR engineering Recently years, studies their results have been elevated and some inspection newspapers are printed inside this field [1,5,11,21]. Generally in the majority of the newspapers, software and prep of all MRFs are analyzed [22,24 ]. Stabilization processes of those fluids have yet to be fully coated within the literatures. Taking in to consideration the increasing applications of magnetorheologi- lipoic fluids in the present businesses of today, it appears crucial to establish an all-inclusive study about improvement and the groundwork of MRFs in addition to their own influence. The issue reported concerning fluids is directly associated from the carrierfluid with sedimentation of iron contaminants. Within this analysis that the focus will be always to give an all-inclusive overview examine and to present the fluids' stabilization processes. A few of one of the MRF software are already introduced Because also the MR outcome in every particular program and the equilibrium are separate from several different software. To get more thorough comprehension of this result and parameters that were productive, Inside this circumstance, also the variations that may be properly utilized for describing why how MRFs habits and rheological behavior are dealt with. Affecting compels on magnetorheological influence. They reasoned that thermal and Hydro Dynamic forces are all currently 
affecting forces that needs to be contemplated in analyzing influence. Inside our prior works $[13,18]$ of both Newtonian and also the goals of various procedures researched non-Newtonian fluids also it's demonstrated that rheometery is just one of one of the absolute most often encountered processes in magnetorheology. Zhang and li [19] evaluated the consequence of friction on fluids theoretically and. Their task demonstrated the two aspects, particularly friction and force power usually affect the MR result. It has been demonstrated that the worries caused to friction is more significant in shear deformations, even though it reaches one-third of their entire anxiety at shear deformations. The reason the reason it's not possible to discount the brute pressure in most 14, That's. In a second exploration, Yamaguchi et al. [20] dedicated to rheological features of the magnetorheological fluid at a magnetic area. They found that elasticity and viscosity of MRFs are affected by area and focus of both particles.

\section{PROPERTIES OF MR FLUIDS}

Result is distinguished with a rise in the viscosity of reveal and also an liquid - ing produce strain as a result of debut. Even the MR result might be managed rheological faculties and from magnetic field strength of liquid components. To put it differently, controllable features of an MRF have been existence of the magnetic area, every particle has been converted to a Di-Pole and creates a string having its particles which provides a structure that was semi-solid and can withstand failure. Differences involving those dipoles that are triggered induce the contaminants to become emptied together the area and shape a columnar composition. The suspension and will impair motion of this liquid. Reinforcement of this magnetic field increases vitality required to over come this specific arrangement [5]. The series arrangement will melt If shear speed surpasses a intense price and also the fluid is going to stream. The strain that MRF maintain in this shear speed is known as yield pressure of this liquid [8]. Produce pressure may be your stress that may be implemented until the MRF movement that's an integral role of the magnetic field [25] and also related to the augmentation in behaviour [1-1 ]. Yield tension as a component in uses of MRFs switch in among 10 and 100 $\mathrm{kPa}$ in a selection of [26]. This variable is dependent upon size, shape supply [27--28]intensity of this employed [8], interactions with creation and also these contaminants of agglomerates [2-9 ].To look apparatus that are magnetorheological and also to predict the method by which they function, an individual could have to locate a connection between shear speed and shear tension from the [thirty ]. Beha- vior of MRFs at the lack of the magnetic field is much like this routine of business fluids," but the metallic particles from those fluids create the fluids focused [25]. A few of their designs will undoubtedly soon likely probably be introduced from these paragraphs.Probably one among the absolute most fundamental factors to spell out the behaviour of magnetorheological fluids is Bingham version [3-1 ] that will be broadly employed to characterize circulation patterns (shear stress vs shear speed) of all magnetorheological fluids. As stated by Bingham version, the produce strain for credited to polarity of particles caused by [25]. At the series - such as arrangement improve viscosity of this

just about every stream curve might be pulled at no shear speed [ 32,33 ] out of interpolation. At one definite occasion, Claracq et al. [ 36 ] have researched that the rheological characteristics of both magnetorheological fluids also also reasoned they stick to Bingham plastic version. The different parameter equation is Casson version [3 9]. Laun and gabriel [40] discovered that Casson version affirms the consequences in precision and can be an even version for design apparatus that were magnetorheological. 1 cause of this particular monitoring is the fact that incline of shear stress vs shear speed in version is just really actually a role of shear speed it shows consistency using consequences of this fluid.Version is really just a 3 parameter version that originated reduce strain of viscoplasticfluids and to spell out flow patterns and is far widespread compared with previous versions [4 1 ]. Some studies about magnetorheological fluids' tech highlight with all the behaviour of those [40,42--44]. Models like the ability law version are suggested to spell out the behaviour of non- Newtonian fluids that aren't widely requested magnefluids [4-5].

\section{APPLICATIONS OF MR FLUIDS}

Uses of MRFs come now in apparatus which have to have ongoing rapid and reversible shift in attributes [5]. As a fluid sets apparatus within connection using an electric platform enabling conclusion of features of this device, apparatus have obtained a distinguished attention throughout the very last decades. Many of they that use magnetor- fluids really are a fresh creation of brakes, clutches and dampers. Magnetorheological dampers as shock-absorbers would be definitely the apparatus with the type [44]. Alternators, electrical power steering pumps, artificial joints, motor mounts, Handle valves propagation, compound software yet many others are several of those illustrations $[11,46]$. Cancer treatment systems and Medication shipping in medication are still a few uses of suspensions [4 5 ].Within an comparatively complete analysis, Bica et al. [2-3 ] learned the prospective uses of magnetorheological suspensions. They discovered elements influencing the operation of all both MRFs. In a second analysis, Meng and Wang [2 4] assessed software and traits of both magnetor fluids. Their poll revealed the 3 issues against usage of MRF technologies in modern apparatus will be their own durability, charge points along with the own settling equilibrium. Possessing no promise to pay most of that software, the followings speak about a few of the uses of fluids. Turczyn and kciuk [1] researched their applications in a variety of businesses as well as houses of MRFs. In a second analysis, Grunwald and Olabi [25] examined faculties of fluids in addition to their own applications. As per their poll, assuring features such as reply of MRF technological innovation user interface involving energy output signal and electrical energy input signal and controllability, create sure they are the tech selection for several software.Dampers: dampers Damper can be actually really just a method to decrease jolt, moreover, to confine motion, to neutralize the brute pressure, etc.. Even a magne- damper can be really actually just a damper that

Published By:

Blue Eyes Intelligence Engineering 
comprisesmagnetorheology fluids and also can be regulated with all magneticfield's ability. As they can employ damping powers into the 16 , dampers are manufactured and also are. A challenge does occur from the device, the damper has the capability to function like a system using parameters predicated on criteria of this fluid at the lack of the magnetic field [44]. MR dampers have software prosthesis get a handle on, from management methods, washing machine harm mitigation in engineer- centric and control of vibrations in bridges [inch].Valves: whenever that the liquid flows throughout the uterus, a magnetic field is put on the induces and also liquid viscosity of the liquid to grow. The change at the viscosity results in immunity against circulation of liquid. The center is raised and stream of this fluid melts down or absolutely ceases. Rosenfeld et al. [4-7] tested framework and operation of magnetorheological along with electrorheological valves last but not least unearthed that operation of this prior considerably relies upon forcing active and force amount of their liquid.Sprucing: Optical sprucing, that has been introduced with Kordonski et al. [9], is understood as the following industrial app of magnetorheological fluids. At the existence of an magnetic field, an structure is formed by magnetic particles and also induce particles to execute the process that is sharpening. Stiffness of the magnetorheologicalfluid and the abrasive power is related to the magnitude of particles. Focus $[48,49]$ and variety of those particles along with parameters that affect caliber of this area [2 4 ].Brakes: Magnetorheological brake can be. A rotational brake at the current clear presence of the magnetic field has the capability to alter the torque fast [fifty ]. The ease and simplicity of management create MRF brakes a selection for wide array of software [51].

\section{CHALLENGES\& RESULTS}

Fluids should attain characteristics to survive in the marketplace of technology applications. Several of those faculties are: performance in a broad range of temperature, chemical stability, stability against sedimentation, reversible flocculation and elevated saturation. An MRF has to reveal high return strain at an low and magneticfield obvious viscosity's existence in the absence of a magnetic field[11,56]. Some of the issues in making a magnetor- fluid is to reduce sedimentation and aggregation of these contaminants.Sedimentation which occur as a result of great density mismatch in between magnetic particles and business liquid, restrict wide spread uses of MRFs. It is thus crucial to generate a stable and uniform distribution and also to overcome Van Der Waals attraction forces among the particles as well [30]. As with other methods that contain contaminants, equilibrium and redistribution of the suspensions is traditionally deemed basic problems at high concentration of particles. There are just two methods to determine sedimentation rate in magnetorheological fluids: measuring the speed of changes in magnetic permeability of the MRF coating and departure laser by means of a pillar of the magnetorheological fluid [30]. However, there is no promis-centric solution to establish the equilibrium of MRFs. Methods for ascertaining for example as scattering gentle and decision of turbidity equilibrium of additional dispersed systems aren't pertinent in these situations, as light for transmission that is negligible and several times make the measurements unreliable. In fluids methods are derived from using $\mathrm{X}$ ray and also gamma ray however they are quite pricey and complicated [6].Particles have to be dispersed once more If sedimentation occurs. Since there is no conventional and repeatable method in this case, and determination of the range of particles that were re-distributed is very hard, an appropriate system have not been demonstrated for redistribution of contaminants far. However, numerous methods are produced by numerous investigators to over come this issue for some degree by modifying MRF compositions, include - ing: diminishing measurement of these particles, addition of thixotropic materials (for example, carbon fibers, including silica nanoparticles along with also organoclays), surfactants, using viscoplastic fluids, or even application of an emulsion as the continuous phase [6]. The difference amongst density of the particles and the carrier liquid, as well as the different size of these contaminants causes the liquid to be prone to sedimentation once not in use. When sedimentation occurs, allure due to the remnant magnetization creates redistribution of the [27]. This happening can be inhibited to some huge range using surfactants and substances such as silica gel, xantham gum, stearate and acids. All these stearates produce an network of strands which seals particles and hastens them. Mean- although, thin carbon fibers are useful with this purpose [5]. A special attention must be devoted into the constituents of these fluids in order to conquer the problems in industrial use of magnetorheological fluids.Erosion is another problem brought on by interparticle contact friction in liquid flow, and it has confined the utilization of magnetic fluids. Carbonyl iron contaminants that are among the most commonly Applied particles from MRFs, reveal an onion-like architecture and their arrangement may be simply altered by friction and/or jolt. Erosion contributes to long-term thickening of their suspension and so decreases in MRFs operation. Much care has been paid to routine remedy for growing magnetorheological fluids lifetime [3-6 ].A number of the parameters that considerably affect equilibrium and redistribution of pollutants inside magnetorheological fluids are both con - centration and density of particles, particle dimensions and shape distribution, sensory modification, coercive subject, characteristics of this bottom liquid, surfactants and also anti-abrasion substances, implemented magnetic area and temperature [22]. Vekas et al. [2-9 ] analyzed the consequence of chemical composition of the fluid and also dipole connections amongst particles about characteristics of the MRF movement. They found that leak faculties are influenced by substance composition than requirements of their environment and system. The following sub sections give qualities and requirements of this makeup of fluids to solve some other troubles, magnetorheological influence that is reduced plus elevated sedimentation. 


\section{CONCLUSION}

Use of fluids - quate is of significance in most businesses. Fluids that are suspensions of particles at a foundation fluid using stabilizer additives, and exhibit behaviour of the material inside the current clear presence of an magnetic field. Obtaining fantastic return anxiety (sturdy magnetorheological influence) and diminishing sedimentation of all both magnetizable particles, as a result of gravity, therefore are just two major hurdles from the circumstance of MRFs. All these issues, which depend upon size, shape, form and quantity portion of these particles affect properties of those fluids. Picking out magnetiz- capable allergens is dependent equilibrium considerations, with company fluid, demanded MR influence therefore forth. But iron micro-particles would be definitely the absolute most contaminants to get period in MRFs. Assortment of iron contaminants leads to elevated saturation magnetization coercivity cost along with also their accessibility.As far as now, tons of processes are launched to increase MR impact in addition to equilibrium. The grade of particle is: diminishing by means of growing the viscosity of business fluid employing large viscose fluids and utilizing nanostructure substances, them with the addition of additive surfactant and changing particle area.Coating the particles is just one system to cut back particle density in addition to connections among the contaminants. Employing this procedure can stability improved believe - although the MR result is going to be paid off. One of the substances coated iron contaminants using resources are used. Still another stabilization process that's only one of one of the absolute most promising types, which enriches result, is connected with a structure of fluids out of suspending micro-particles got. With a mix of microparticles and nanoparticles makes bonds. Existence decreases sedimentation and of nanoparticles from the bottom fluid improves viscosity of their bottom liquid.Some reports demonstrate the provider fluid plays a part within magnetorheology. With fluids leads to minimise the density gap between your metallic and basefluid particles, while the effective element in uncertainty and sedimentation of those suspensions. The viscosity of the fluids grown from magneticfield's lack that isn't desired. Silicon oil is called the very first selection owing to its accessibility for your fluids groundwork, very low priced, very low viscosity therefore forth. Some studies centered on applying additives which may enhance MR and equilibrium result. So far have yet to be understood. It appears that one of surfactants and all additives, ellagicorganoclay acid along with fumed silica are substances.Several of these techniques reduce consequence and therefore return anxiety, and also research inside this circumstance looks needed. Despite many research Conducted as magnetorheologicalfluids discovery, inside this region, it seems crucial to chance upon a makeup of those suspensions that may be more costeffective and stable. Advancement of fluids apps, desire insertion of those fluids in addition to additional search work for MR impact. Among all together with nano-wires with a mixture of fluids along with ferrofluids and adding stabilizers could possibly be accounted as purification processes that may enhance equally equally stable result. A number of those limitation along with nanowires and nanoparticles into magnetor- fluids, along with also by using stabilizers, more experiments that may function as topic of research studies are needed.

\section{REFERENCE}

1. A. Muhammad, Y. Xiong-liang, and D. Zhong-chao, "Review of magnetorheological (MR) fluids and its applications in vibration control," J. Mar. Sci. Appl., vol. 5, no. 3, pp. 17-29, Sep. 2006.

2. B. A. Gordeev, S. N. Okhulkov, and A. S. Plekhov, "Error estimate at magnetorheological transformer calculation tests by flooding methods," in INTERNATIONAL CONFERENCE ON EMERGING TRENDS IN ENGINEERING, SCIENCE AND TECHNOLOGY (ICETEST - 2015), 2016, vol. 24, pp. 394-398.

3. B. J. Park, F. F. Fang, and H. J. Choi, "Magnetorheology: materials and application," Soft Matter, vol. 6, no. 21, pp. 5246-5253, 2010.

4. X. Q. Ma, S. Rakheja, and C.-Y. Su, "Development and relative assessments of models for characterizing the current dependent hysteresis properties of magnetorheological fluid dampers," J. Intell. Mater. Syst. Struct., vol. 18, no. 5, pp. 487-502, May 2007.

5. J. Q. Zhang, J. P. Ou, J. G. Lu, and Q. C. Kong, "Study on smart damper in suspension system of tracked armored vehicle," in ISTM/2001: 4TH INTERNATIONAL SYMPOSIUM ON TEST AND MEASUREMENT, VOLS 1 AND 2, CONFERENCE PROCEEDINGS, 2001, pp. 1021-1024.

6. L. Yongzhi, L. Xinhua, and L. Hao, "The Monte Carlo simulation to magnetic particles of magnetorheological fluids," in CEIS 2011, 2011, vol. 15.

7. R. Ahamed, M. M. Ferdaus, and Y. Li, "Advancement in energy harvesting magneto-rheological fluid damper: A review," KOREA-AUSTRALIA Rheol. J., vol. 28, no. 4, pp. 355-379, Nov. 2016

8. S. A. Wahid, I. Ismail, S. Aid, and M. S. A. Rahim, "Magneto-rheological defects and failures: A review," in 2ND INTERNATIONAL MANUFACTURING ENGINEERING CONFERENCE AND $3 R D$ ASIA-PACIFIC CONFERENCE ON MANUFACTURING SYSTEMS (IMEC-APCOMS 2015), 2016, vol. 114.

9. G. K. Auernhammer, "Magnetorheological gels in two and three dimensions: understanding the interplay between single particle motion, internal deformations, and matrix properties," Arch. Appl. Mech., vol. 89, no. 1, SI, pp. 153-165, Jan. 2019.

10. N. A. Mutalib, I. Ismail, S. M. Soffie, and S. N. Aqida, "Magnetorheological finishing on metal surface: A review," in IST INTERNATIONAL POSTGRADUATE CONFERENCE ON MECHANICAL ENGINEERING (IPCME2018), 2019, vol. 469.

11. W. Tang, J. Zheng, J. G. Lu, J. Q. Zhang, and Q. H. Tang, "MR materials and application of MR fluid dampers in mechanical engineering," in ISTM/2003: $5 T H$ INTERNATIONAL SYMPOSIUM ON TEST AND MEASUREMENT, VOLS 1-6, CONFERENCE PROCEEDINGS, 2003, pp. 1641-1644.

12. S. Genc and B. Derin, "Field Responsive Fluids - a Review," in INNOVATION IN MATERIALS SCIENCE II, vol. 521, Nadagouda, M and Connelly, M and Derin, B and Li, HP and Sekhar, JA, Ed. 2012, pp. 87-99.

13. L. Vekas, "Ferrofluids and Magnetorheological Fluids," in SMART MATERIALS \& MICRO/NANOSYSTEMS, 2009, vol. 54, pp. 127-136.

14. J.-S. Oh and S.-B. Choi, "State of the art of medical devices featuring smart electro-rheological and 
magneto-rheological fluids," J. KING SAUD Univ. Sci., vol. 29, no. 4, pp. 390-400, Oct. 2017.

15. G. Bossis, E. Coquelle, and P. Kuzhir, "Adaptive magnetorheological materials," Ann. Chim. DES Mater., vol. 29, no. 6, pp. 43-54, 2004.

16. C. Scherer and A. M. F. Neto, "Ferrofluids: Properties and applications," BRAZILIAN J. Phys., vol. 35, no. 3A, pp. 718-727, Sep. 2005.

17. F. J. Galindo-Rosales, "Complex Fluids in Energy Dissipating Systems,” Appl. Sci., vol. 6, no. 8, Aug. 2016.

18. B. Hallock, B. Messner, C. Hall, and C. Supranowitz, "Improvements in large window and optics production," in WINDOW AND DOME TECHNOLOGIES AND MATERIALS X, 2007, vol. 6545.

19. S. H. Piao, C. Y. Gao, and H. J. Choi, "Pickering emulsion-polymerized conducting polymer nanocomposites and their applications," Chem. Pap., vol. 71, no. 2, pp. 179-188, Feb. 2017.

20. J. Liu, K. Xia, and C. Zhu, "The Research and Application of Nonlinear Control algorithms Based on magnetorheological damper," in 2009 SECOND INTERNATIONAL CONFERENCE ON FUTURE INFORMATION TECHNOLOGY AND MANAGEMENT ENGINEERING, FITME 2009, 2009, p. 323+.

21. J. de Vicente, D. J. Klingenberg, and R. Hidalgo-Alvarez, "Magnetorheological fluids: a review," Soft Matter, vol. 7, no. 8, pp. 3701-3710, 2011.

22. G. Jin, M. K. Sain, K. D. Pham, B. F. Spencer, and J. C. Ramallo, "Modeling MR-dampers: A nonlinear blackbox approach," in PROCEEDINGS OF THE 2001 AMERICAN CONTROL CONFERENCE, VOLS 1-6, 2001, pp. 429-434

23. W. Jin-Bo and W. Wei-Jia, "Research progress of field-inducedd soft smart materials," ACTA Phys. Sin., vol. 65, no. 18, Sep. 2016.

24. F. Imaduddin, S. A. Mazlan, and H. Zamzuri, "A design damper," Mater. Des., vol. 51, pp. 575-591, Oct. 2013. Materials, modelling and applications," J. Ind. Eng. Chem., vol. 10, no. 7, pp. 1132-1145, Dec. 2004.

26. B. J. Park, F. F. Fang, K. Zhang, and H. J. Choi, "Polymer-coated magnetic carbonyl iron microparticles and their magnetorheological characteristics," KOREAN J. Chem. Eng., vol. 27, no. 2, pp. 716-722, Mar. 2010.

27. F. Wittbracht, A. Weddemann, B. Eickenberg, and A. Huetten, "On the direct employment of dipolar particle interaction in microfluidic systems," Microfluid. Nanofluidics, vol. 13, no. 4, SI, pp. 543-554, Oct. 2012.

28. A. K. A. Silva, E. L. Silva, A. S. Carrico, and E. S. T. Egito, "Magnetic carriers: A promising device for targeting drugs into the human body," Curr. Pharm. Des. vol. 13, no. 11, pp. 1179-1185, 2007.

29. A. A. Alghamdi, R. Lostado, and A.-G. Olabi, "Magneto-Rheological Fluid Technology," in MODERN MECHANICAL ENGINEERING: RESEARCH, DEVELOPMENT AND EDUCATION, Davim, JP, Ed. 2014, pp. 43-62.

30. S. D. Jacobs, "International innovations in optical finishing," in CURRENT DEVELOPMENTS IN LENS DESIGN AND OPTICAL ENGINEERING V, 2004, vol. 5523, pp. 264-272.

31. K. I. Gkatzogias and A. J. Kappos, "Semi-Active Control Systems in Bridge Engineering: A Review of the Current State of Practice," Struct. Eng. Int., vol. 26, no. 4, pp. 290-300, Nov. 2016.

32. Y. D. Liu, C. H. Hong, and H. J. Choi, "Polymeric colloidal magnetic composite microspheres and their magneto-responsive characteristics," Macromol. Res. vol. 20, no. 12, pp. 1211-1218, Dec. 2012.

33. X. Wang and J. Cai, "Magnetorheological elastomer: and modelling review of rotary magnetorheological

25. H. See, "Advances in electro-rheological fluids:

State and Application," in BIOTECHNOLOGY, CHEMICAL AND MATERIALS ENGINEERING, PTS 1-3, 2012, vol. 393-395, pp. 161-165.

34. N. Q. Hung, D. B. Tri, V. Van Cuong, and S.-B. Choi, "Design and Simulation of a New Bidirectional Actuator for Haptic Systems Featuring MR Fluid," in ACTIVE AND PASSIVE SMART STRUCTURES AND INTEGRATED SYSTEMS 2017, 2017, vol. 10164, no. 1.

35. X. P. Do and S.-B. Choi, "High Loaded Mounts for Vibration Control Using Magnetorheological Fluids: Review of Design Configuration," Shock Vib., 2015.

36. D. Golini, W. I. Kordonski, P. Dumas, and S. Hogan, "Magnetorheological finishing (MRF) in commercial precision optics manufacturing," in OPTICAL MANUFACTURING AND TESTING III, 1999, vol. 3782, pp. 80-91.

37. B. F. Spencer, "Technological frontiers of smart damping for protection of civil infrastructure," in PROCEEDINGS OF THE SEVENTH INTERNATIONAL SYMPOSIUM ON STRUCTURAL ENGINEERING FOR YOUNG EXPERTS, VOLS 1 AND 2, 2002, pp. 3-15.

38. M. Zrinyi, "Colloidal particles that make smart polymer composites deform and rotate," COLLOIDS SURFACES A-PHYSICOCHEMICAL Eng. Asp., vol. 382, no. 1-3, SI, pp. 192-197, Jun. 2011.

39. H. J. Jung, B. F. Spencer, Y. Q. Ni, and I. W. Lee, "State-of-the-art of semiactive control systems using MR fluid dampers in civil engineering applications," Struct. Eng. Mech., vol. 17, no. 3-4, pp. 493-526, 2004.

40. G. A. Dominguez, M. Kamezaki, and S. Sugano, "Proposal and Preliminary Feasibility Study of a Novel ToroidalMagnetorheological Piston," IEEE-ASME Trans. MECHATRONICS, vol. 22, no. 2, pp. 657-668, Apr. 2017.

41. W. L. Zhang, Y. D. Liu, and H. J. Choi, "Field-responsive smart composite particle suspension: materials and rheology," KOREA-AUSTRALIA Rheol. J., vol. 24, no. 3 , pp. 147-153, Sep. 2012.

42. M. Yang and P. Qiao, "High energy absorbing materials for blast resistant design," in BLAST PROTECTION OF CIVIL INFRASTRUCTURES AND VEHICLES USING COMPOSITES, Uddin, N, Ed. 2010, pp. 88-119.

43. M. Ismail, F. Ikhouane, and J. Rodellar, "The Hysteresis Bouc-Wen Model, a Survey," Arch. Comput. METHODS Eng., vol. 16, no. 2, pp. 161-188, Jun. 2009.

44. M. Eshaghi, R. Sedaghati, and S. Rakheja, "Dynamic characteristics and control of magnetorheological/electrorheological sandwich structures: A state-of-the-art review," J. Intell. Mater. Syst. Struct., vol. 27, no. 15, pp. 2003-2037, Aug. 2016.

45. A. Ghaffari, S. H. Hashemabadi, and M. Ashtiani, "A review on the simulation and modeling of magnetorheological fluids," J. Intell. Mater. Syst. Struct., vol. 26, no. 8, pp. 881-904, May 2015.

46. J. Wang and G. Meng, "Magnetorheological fluid devices: principles, characteristics and applications in mechanical engineering," Proc. Inst. Mech. Eng. PART L-JOURNAL Mater. Appl., vol. 215, no. L3, pp. 165-174, 2001.

47. D. Susan-Resiga and L. Vekas, "FROM HIGH MAGNETIZATION FERROFLUIDS TO NANO-MICRO COMPOSITE MAGNETORHEOLOGICAL FLUIDS: PROPERTIES AND APPLICATIONS," Rom. REPORTS Phys., vol. 70 no. 1,2018

48. H. Wu, Z. C. Xu, J. B. Wu, and W. J. Wen, "Research progress of field-induced soft smart materials," Int. J. Mod. Phys. B, vol. 32, no. 18, SI, Jul. 2018. 
49. M. Braz Cesar and R. de Barros, "PROPERTIES AND NUMERICAL MODELING OF MR DAMPERS," in ICEM15: 15TH INTERNATIONAL CONFERENCE ON EXPERIMENTAL MECHANICS, 2012.

50. D. E. Barber and P. Sheng, "Award-Winning Innovation in Controllable Fluids," in ACTUATOR 10, CONFERENCE PROCEEDINGS, 2010, p. 533+.

51. I. Bica, Y. D. Liu, and H. J. Choi, "Physical characteristics of magnetorheological suspensions and their applications," J. Ind. Eng. Chem., vol. 19, no. 2, pp. 394-406, Mar. 2013.

52. G. Pan, H. Matsuhisa, and Y. Honda, "Analytical model of a magnetorheological damper and its application to the vibration control," in IECON 2000: 26TH ANNUAL CONFERENCE OF THE IEEE INDUSTRIAL ELECTRONICS SOCIETY, VOLS 1-4: 21ST CENTURY TECHNOLOGIES AND INDUSTRIAL OPPORTUNITIES, 2000, pp. 1850-1855.

53. A. Olaru, D. Calarasu, and M. Afrasinei, "THE CONTROL OF THE FORCE ACTING ON A SPOOL SLIDE VALVE USING THE PROPERTIES OF THE MAGNETORHEOLOGICAL FLUIDS WITH APPLICATIONS TO THE SERVO-ELEMENTS," in MODTECH 2012: NEW FACE OF T M C R, VOLS I AND II, 2012, pp. 693-696.

54. I. Bahiuddinet al., "A new constitutive model of a magneto-rheological fluid actuator using an extreme learning machine method," SENSORS AND ACTUATORS A-PHYSICAL, vol. 281, pp. 209-221, Oct. 2018.

55. G. Filipcsei, I. Csetneki, A. Szilagyi, and M. Zrinyi, "Magnetic field-responsive smart polymer composites," in OLIGOMERS POLYMER COMPOSTIES MOLECULAR IMPRINTING, vol. 206, 2007, pp. 137-189.

56. X. Zhu, X. Jing, and L. Cheng, "Magnetorheological fluid dampers: A review on structure design and analysis," $J$. Intell. Mater. Syst. Struct., vol. 23, no. 8, pp. 839-873, May 2012. 